\title{
¿Robots con derechos?: la frontera entre lo humano y lo no-humano. Reflexiones desde la teoría de los derechos humanos*
}

\section{Juan Francisco Díez Spelz**}

\begin{abstract}
RESUMEN
El presente documento aborda uno de los problemas más apremiantes de la teoría de los derechos humanos: la titularidad de los mismos. Es decir, quiénes pueden ser titulares de estos derechos. Las implicaciones de la respuesta que se dé a esta pregunta tienen efectos incluso en nuestra comprensión acera de la frontera entre lo humano y lo no-humano en el ámbito juridico. En este sentido, se reflexiona en torno a si es congruente el atribuir los mismos en ciertos casos a robots o sistemas de Inteligencia Artificial, con el fin de analizar las implicaciones que esto supondría. La idea de fondo será el preguntarse acerca de si a través de los esfuerzos por atribuir derechos humanos a este tipo de realidades, se logra el objetivo primordial de los mismos, es decir, el respeto de la dignidad humana.
\end{abstract}

\section{PALABRAS CLAVE}

Derechos humanos, inteligencia artificial, robots, dignidad humana, persona jurídica electrónica.

\begin{abstract}
This article addresses one of the most imperative problems for a theory of human rights: entitelement. That is, who is entiteled to these rights. The implications of any answer given to this question, may have effects in the manner in which we understand the limits between what is human and what it is not in the legal context. In this sense, it would be reflected about whether it is consistent for robots or Al systems to be entiteled to human rights, and what the possible implications of this possibility may be. The document will analyse if the attribution of human rights to these entities is coherent with the idea of human dignity.
\end{abstract}

\section{KEYWORDS}

Human rights, artificial intelligence, robots, human dignity, electronic juridical person.

\footnotetext{
*Artículo de Investigación postulado el 30 de abril de 2020 y aceptado el 3 de noviembre de 2020

**Profesor investigador en la Facultad de Derecho de la Universidad Panamericana, Ciudad de México. (jfdiez@ up.edu.mx) orcid.org/0000-0003-0376-9272
} 


\section{SUMARIO}

1. Introducción

2. Planteando el problema ¿Hacia una "personalidad jurídica electrónica"?

3. Hacia una teoría de los derechos humanos en el contexto de la Inteligencia Artificial

4. Lo humano y lo no-humano: hacia una reflexión en torno a robots y derechos humanos

5. Conclusión

6. Bibliografía

\section{Introducción}

En el libro El Cerdo que quería ser jamón, Julian Baggini presenta un experimento mental que plantea la cuestión que analizaremos en el presente artículo. En el capítulo titulado "Free Simone", un robot "esclavo" inicia procedimiento contra sus dueño con base en el Artículo 4 del Convenio Europeo para la protección de Derechos Humanos y Libertades Fundamentales por considerar que se le ha violado su derecho a la libertad y prohibición de trabajos forzados, tomando en cuenta que es también una persona y que como tal debe ser titular de derechos, al igual que cualquier ser humano. ${ }^{1}$

Partimos de que vivimos en un tiempo tanto de derechos, como de ciencia y tecnología. ${ }^{2}$ La confluencia de estos dos paradigmas hace que la cuestión de los derechos humanos en el contexto de la robótica, haya llevado a algunas voces a plantearse si robots inteligentes y autónomos pudieran llegar a ser "personas jurídicas electrónicas" y, con ello, ser titulares de derechos humanos, o al menos derechos similares a éstos. Esto hace pensar en ejemplos como el del párrafo anterior. Aun cuando continuemos en el estado de la experimentación mental para afrontar este fenómeno, en este artículo se propone una reflexión acerca de la posible atribución de personalidad o derechos desde una teoría de los derechos humanos, lo que supone pensar acerca de la titularidad de los mismos.

La tesis que se pretenderá demostrar es que, independientemente de la atribución o no de derechos o personalidad a cierto tipo de entes, como robots o sistemas de IA, la problemática que permanece en el fondo de estas cuestiones es el preguntarse por la frontera entre lo "humano" y lo "no-humano", así como por el paradigma de cómo los derechos humanos pueden responder a los

\footnotetext{
${ }^{1}$ Cfr. Baggini, Julian, El cerdo que quería ser jamón: y otros noventa y nueve experimentos para filósofos de salón, Paidós, 2007, passim.

${ }^{2}$ Cfr. Salardi, Silvia, "Robótica e Inteligencia artificial: retos para el derecho", en Revista Derechos y Libertades, no. 42, enero 2020, Disponible en: doi: 10.14679/1158, p. 211.
} 
procesos de "humanización”. Para ello, comenzaremos planteando el problema en torno a la posible atribución de "personalidad jurídica" a robots y sistemas de IA. En una segunda sección se presentan ciertos elementos de una teoría de los derechos humanos en éste contexto, para en la tercera sección reflexionar en torno a la frontera entre lo humano y lo no humano con una propuesta hacia la humanización del derecho en estos ámbitos.

\section{Planteando el problema ¿Hacia una "personalidad jurídica electrónica”?}

El presente artículo busca reflexionar acerca de la posibilidad de que robots o sistemas de Inteligencia Artificial (IA) puedan considerarse como titulares de cierto tipo de derechos - humanos o "robóticos"3- derivado de un reconocimiento de una probable "personalidad jurídica". Esta es una problemática que, más allá de resolver la cuestión acerca de la atribución o no de derechos a diversos tipos de "personalidades", supone un reto para la comprensión de la naturaleza e implicaciones de los derechos, así como de sus efectos prácticos. Es decir, supone preguntarnos por el significado de "tener derechos", así como el fundamento de su atribución en realidades como la dignidad o la conciencia.

Los avances en IA y robótica al menos nos plantean un escenario donde podemos cuestionarnos los fundamentos, no sólo de los derechos -humanos o de otro tipo- sino en general del Estado de Derecho. En efecto, Tasioulas reconoce que la innovación tecnológica supone uno de los mayores retos que en la actualidad se le presentan al Estado de Derecho, sobre todo por la tentación de utilizarlos para "mejorar lo humano" o "mejorar la forma en que se aplica el derecho". De cualquier forma, no debe perderse de vista que los mismos son creaciones humanas y, por ello, deficientes. ${ }^{4}$ Entonces, nuestra esperanza en los mismos debe ser mesurada. Aún así, la posibilidad de que logren altos niveles de "inteligencia” y “autonomía” justifica la preocupación en torno a su status jurídico.

En este sentido, la reflexión que se propone implica, como lo reconoce Michel Frommkin, el cuestionarnos acerca de la naturaleza tanto de un robot,

\footnotetext{
${ }^{3}$ García, José, "¿Tienen que tener los robots los mismos derechos y obligaciones que nosotros?", en La Información, 28 de enero 2018, Disponible en:<https://www.lainformacion.com/economia-negocios-y-finanzas/tienen-que-tener-los-robots-los-mismos-derechos-y-obligaciones-que-nosotros/6340964/>

${ }^{4}$ Cfr. Tasioulas, John, "The Rule of Law", en Tasioulas, J. (Ed)., The Cambridge Companion to The Philosophy of Law, Cambridge, 2020, pp. 131-132.
} 
como la de un derecho subjetivo en particular, o la del derecho en general. ${ }^{5}$ Aparentemente estamos en un contexto donde no basta realizar la distinción jurídica tradicional entre personas y cosas, sino que se inserta una nueva posibilidad derivada de los avances tecnológicos en temas de machine learning, autonomía y capacidades de la inteligencia algorítmica en sus relaciones con otros sujetos de derecho. De hecho, Yuval Noah Harari plantea este problema como uno de los principales retos para nuestro siglo, incluso suponiendo que podría, en algún momento, hacer que cambie nuestro concepto de humanidad. ${ }^{6}$

De esta forma, el marco en el que se desarrolla el análisis sobre la innovación tecnológica y la posible "personalidad" de entidades no humanas pero creadas por el hombre está inscrito, de acuerdo con Silvia Salardi en la relación entre ciencia, tecnología y derecho. ${ }^{7}$ En este sentido, el derecho debe buscar la medida entre los intereses de la investigación o el desarrollo científico y los derechos o libertades fundamentales, preguntándose si “¿es el Derecho el que tiene que "dar forma" a las tecnologías o son estas las que "modelan" al Derecho?" En todo caso, la pregunta está inscrita en el reconocimiento jurídico de quién es persona y lo que implica reconocer personalidad a una determinada entidad en términos de igualdad de trato y consideración. ${ }^{9}$

Desde el año 2013 se ha planteado en Europa la pregunta acerca de los "derechos de los robots", y sobre todo acerca de la naturaleza de los mismos y la conveniencia de dotarlos de un estatus distinto a los aparentemente conocidos ${ }^{10}$-persona física, persona jurídica, animal u objeto-, como "personas jurídicas electrónicas”. ${ }^{11}$ Aunque en un dictamen del Comité Económico y Social Europeo niega esta posibilidad, por los riesgos morales que puede suponer, primando en este sentido el carácter instrumental de la Inteligencia Artificial, ${ }^{12}$

\footnotetext{
${ }^{5}$ Cfr. Froomkin, A. Michel, "Prólogo" en Barrio Andrés, Moisés, Derecho de los Robots, Madrid, Wolters Kluwer, 2a Edición, 2019.

${ }^{6}$ Cfr. Harari, Yuval Noah, 21 lecciones para el siglo XXI, México. Debate, 2020, p. 77.

${ }^{7}$ Cfr. Salardi, Silvia, "Robótica e Inteligencia artificial...Op. Cit., p. 211.

${ }^{10}$ Barrio Andrés, citando al psicólogo Peter Kahn, concluye que los robots podrian pertenecer a una categoría ontológica nueva. Esto al menos de acuerdo a la percepción que varias personas tienen al respecto. Cfr. Kahn, Peter: "The new ontological category hypothesis in human-robot interaction", en Proceedings of the seventh annual ACM/ IEEE international conference on Human-Robot Interaction, Boston, Massachusetts, 2012; en Barrio Andrés, Moisés, "Hacia Una Personalidad Electrónica Para Los Robots." Revista de Derecho Privado, no. 2, Marzo 2018, p. 100.

${ }^{11}$ Cfr. Aransay Alejandre, Ana Maria, "Antecedentes y propuestas para la regulación jurídica de los robots", en Barrio Andrés, Moisés, Derecho de los Robots, Madrid, Wolters Kluwer, 2a Edición, 2019.

12 "3.33. (...) El CESE se opone a cualquier tipo de estatuto jurídico para los robots o sistemas de IA por el riesgo moral inaceptable que ello conlleva. La legislación en materia de responsabilidad tiene un efecto correctivo y preventivo que podria desaparecer" en cuanto el riesgo de responsabilidad civil dejase de recaer sobre el autor por haberse
} 
lo que comienza a vislumbrarse es “...un reto en la concepción de la máquina y del propio ser humano en un marco legislativo que necesariamente abarca la ética y la filosofía". ${ }^{13}$

De hecho, las reflexiones relativas a este entorno enmarcado en la sociedad del "conocimiento y la información" han llevado a algunos autores a justificar el surgimiento de nuevos "derechos" vinculados con el ciberespacio, la informática y la tecnología. No sólo eso, sino que se plantea, al hablar incluso de una cuarta, quinta y hasta sexta generación de derechos humanos, de atribuir estos a entidades no humanas. Por un lado, a animales o recursos naturales en el caso de la "cuarta generación", pero también a sistemas de IA o robots, por la posibilidad de que puedan presentar conductas autárquicas disociadas del progrmador en el caso de una "quinta generación". ${ }^{14}$

Sin embargo, el planteamiento no puede ser tan sencillo como únicamente reconocer "nuevos derechos" al proponer generaciones de los mismos. El problema de la atribución de personalidad y, sobre todo de relación ontológica entre seres humanos y otras realidades persiste. De hecho, en contextos donde se desarrollen máquinas súper inteligentes, Sergio Cotta advierte el peligro de que el ser humano llegue a sentirse menos funcional e inferior a las mismas, aun cuando hayan sido inventos suyos y comience una artificialización de sí mismo. ${ }^{15}$ Estos son también los retos que presenta el transhumanismo, especialmente refiriéndose a la mejora del ser humano o al alcance de una singularidad tecnológica por parte de determinadas máquinas. ${ }^{16}$

En este contexto, la IA puede entenderse como aquellos sistemas creados por el ser humano, que pueden hacer predicciones, recomendaciones, decisiones que influyen tanto en ámbitos virtuales como reales, funcionando con distintos niveles de autonomía. ${ }^{17}$ El término "inteligencia" hace referencia a una

\footnotetext{
transferido al robot (o sistema de IA). Además, una forma jurídica así sería susceptible de uso y aplicación indebidos. La comparación con la responsabilidad limitada de las sociedades no es válida, puesto que el responsable en última instancia es siempre una persona física...". Comité Económico y Social Europeo, "Dictamen del Comité Económico y Social Europeo sobre la «Inteligencia artificial: las consecuencias de la inteligencia artificial para el mercado único (digital), la producción, el consumo, el empleo y la sociedad», Pleno No. 526, 2917/C 288/01 31 mayo 2017.

${ }_{13}$ Aransay Alejandre, Ana María, "Antecedentes... Op. Cit.

${ }^{14}$ Cfr. Medina Parra, Rosa Isabel, "Derechos humanos en México: entre la modernidad, posmodernidad y ultramodernidad", en Revista de Ciencias Sociales y Humanidades, Volumen 29, Número 57, Enero-Junio 2020, Disponible en: DOI: http://dx.doi.org/10.20983/noesis.2020.1.7, p. 161.

${ }^{15}$ Cfr. Cotta, Sergio. La sfida tecnológica, Bologna, II Mulino, 1968, p. 80.

${ }^{16}$ Cfr. Vinge, Vernor, "Technological singularity", en More, Max y Vita-More, Natasha, The transhumanist reader, Oxford, Wiley-Blackwell, 2013. Véase también Agar, Nicholas, Truly human enhancement; A philosophical defense of Limits, Londres. The MIT Press, 2014.

${ }^{17}$ Cfr. Campuzano Gallegos, Adriana, Inteligencia Artificial para abogados. Ya es tiempo..., México, Thomson Reuters, 2019, pp. 10-11.
} 
cualidad (-ia) del que (-nt-) sabe escoger (legere) entre (inter) varias opciones. ${ }^{18}$ Es decir, supone una capacidad de algún ente de discernir entre varias opciones y de razonar de manera práctica. Incluso con efectos éticos en la naturaleza y consecuencias de las acciones. ${ }^{19}$

Sin pronunciarnos en esta oportunidad acerca de si efectivamente una máquina puede ser inteligente en el mismo sentido que un ser humano, podemos de cualquier manera reconocer la existencia de una IA estrecha o débil, diseñada únicamente para realizar ciertas tareas de manera limitada y automatizada, como predicción de compras, publicidad dirigida, asistente virtuales, entre otros, y el de una IA fuerte o general, que podrían operar con autonomía volitiva y capacidad de improvisación, reconocimiento de emociones e incluso conciencia propia. ${ }^{20}$ Esta última es la que, aunque no desarrollada aún, supone mayores retos para plantearnos si, por su nivel de "inteligencia", pudieran ser acreedores de derechos similares a los "humanos".

De la referencia anterior se desprenden dos términos que son muy relevantes para la reflexión en torno a la naturaleza, alcances y efectos de la IA en términos jurídicos: inteligencia y conciencia. En cuanto a la inteligencia, ya Nick Bostrom reconoce la posibilidad de sistemas de este tipo al menos de emular la inteligencia humana, sobre todo hacia esquemas de IA fuerte, con la problemática que podría implicar en cuanto a la incertidumbre que generarían las decisiones tomadas por algoritmos. ${ }^{21}$ Pero sin ir por lo pronto tan lejos, al hablar de inteligencia tenemos primero que reconocer la existencia de inteligencia animal, humana y artificial junto con el problema de la consciencia. ${ }^{22}$ En cualquiera de los casos, tanto en el caso animal, como en el humano o en el de ciertos sistemas, la inteligencia se referiría a la capacidad de resolver ciertos problemas evaluando entre opciones. ${ }^{23}$ Sin embargo, no en todos los casos se da el fenómeno de la consciencia, al menos en su factor moral, como mencionaremos más adelante.

${ }^{18}$ Cfr. "Etimologia de inteligencia", en Diccionario Etimológico Español en Línea, Disponible en: <http://etimologias. dechile.net/?inteligencia>.

${ }^{19}$ Para un análisis ético del razonamiento práctico propio de los seres humanos, Cfr. García Huidobro, Joaquín, El anillo de Giges; Una introducción a la tradición central de la ética, México, Notas Universitarias, 2020, pp. 157-161

${ }^{20}$ Cfr. Campuzano Gallegos, Adriana, Inteligencia Artificial...Op. Cit., pp. 13-14 y 29.

${ }^{21}$ Cfr. Bostrom, Nick, Superinteligencia: caminos, peligros, estrategias, Teell Editorial, 2016, pp. 18-23.

${ }_{22}$ Cfr. Lexcellent, Christian, Artificial Intelligence versus Human Intelligence; Are Humans Going to Be Hacked?, Cham, Springer, 2019, p. 5.

${ }^{23}$ Cfr. Ibid. Lexcellent también identifica, citando a Stefano Mancuso y a Alessandra Viola en el libro "Brilliant Green", la existencia de una inteligencia especifica en las plantas, ya que las mismas forman sistemas complejos entre ellas donde también deben tomar decisiones en cuanto al uso de recursos o la respuesta a amenazas externas. Cfr. Íbidem, pp. 45-49 
La inteligencia "empleada" por sistemas algorítmicos para la resolución de problemas aún ahora se entiende como una emulación de la humana, por su vinculación con el programador. De cualquier modo, los avances en estos sistemas, aun cuando se reconozcan como "simulaciones" de la inteligencia humana, son sorprendentes en reconocimiento de patrones, reconocimiento de voz o toma de decisiones al elegir o trasmitir información, de forma que pueden llegar también a simular sentimientos y hasta consciencia, con las implicaciones éticas tan profundas que esto podría suponer. ${ }^{24}$ Sin ahondar demasiado, los efectos del uso de estos avances se pueden hacer sentir en cuestiones como pérdida de trabajos, racismo, la democracia, la vigilancia o el espionaje. ${ }^{25}$

En tanto plantas, animales, humanos o sistemas artificiales podamos ser considerados como "solucionadores de problemas" y, por ello, inteligentes en algún sentido, una de las principales diferencias que distinguen a sistemas de IA con la inteligencia humana es que, de acuerdo con Lexcellent, los primeros parecería que sólo pueden desarrollar inteligencia matemática basada en algoritmos y, por lo tanto depender de las instrucciones dotadas por un programador, mientras que los humanos contaríamos también con un "inteligencia heurística" que nos permite elegir aquello que parece más efectivo en una situación dada, con intuición, sin necesidad de explorar todas las posibilidades; sólo las más favorables o probables. ${ }^{26}$ Por ahora parece que en cualquier caso, la IA tanto débil como fuerte, se reduce al aspecto matemático o lógico propio de los algoritmos. ${ }^{27}$

De cualquier manera, siguiendo de nuevo a Bostrom, aunque las aplicaciones de IA se encuentren dentro del terreno de la simulación de actividades intelectuales del ser humano, uno de los riesgos que se presentan para la probable consideración de una personalidad al menos para algunos de estos sistemas se inscribe en la posibilidad de que los mismos mejoren las capacidades humanas en algunos aspectos y hasta en la probable manipulación de conceptos o reglas

\footnotetext{
${ }^{24}$ Cfr. Íbidem, pp. 6-14.

${ }^{25}$ Cfr. Íbidem, pp. 30-36.

${ }^{26}$ Cfr. Íbidem, p. 15. Para esto, Lexcellent cita y analiza el pensamiento de Karl Popper.

27 Los algoritmos tienen un aspecto lógico relevante. De hecho, en gran medida podrian ser clasificados como entidades matemáticas y lógicas que primordialmente utilizan proposiciones o razonamientos condicionales (de "si, entonces"). Por ello, el papel del programador es esencial, ya que dota de contenido a estos razonamientos. De cualquier modo, puede perderse control en el desarrollo práctico de las hipótesis programadas, a través del aprendizaje que realiza la máquina. Cfr. Veatch, William S., The New Logic of the Law; Building a Foundation for Artificial Intelligence in the Law, Kindle Edition, 2018.
} 
por parte de los mismos, sobre todo cuando se puedan simular los aspectos heurísticos de la inteligencia humana. ${ }^{28}$

El problema se complica cuando pasamos del terreno de la inteligencia al de la conciencia. ${ }^{29}$ Ya no es el terreno únicamente de la solución de problemas, sino del percatarse de los pensamientos y del propio yo; en últimas cuentas, el problema de la mente humana. No es lo mismo la "consciencia" como una forma de "percatarse" del propio yo y de la acción, que la "conciencia" como la propiedad que permite a la mente distinguir entre el bien y el mal, de conocer sus necesidades y querencias en un aspecto temporal que permita forjar un ser "autobiográfico". ${ }^{30}$

En el contexto de los sistemas algorítmicos un reto todavía pendiente en la conformación de su naturaleza y de la manera que los comprendemos es determinar su grado de conciencia. Aún cuando Damasio supone en principio que sí se podría crear un artefacto consiente, sirviéndonos de la tecnología avanzada y de datos neurobiológicos ${ }^{31}$ existen objeciones a esta postura. Una de ellas, planteada por John Searle supone que un sistema de IA puede utilizar o traducir símbolos para resolver problemas, pero sin comprenderlos, a semejanza de una persona encerrada en una "habitación china" donde adquiere con ayuda de un diccionario la capacidad de traducir del chino al inglés a través de los símbolos de las palabras, pero sin entender el idioma. ${ }^{32}$

Las consideraciones anteriores dificultan o al menos presentan retos para la comprensión de la naturaleza y alcances de sistemas de IA en su contexto algorítmico. Más cuando estos se involucran o están presentes en el ámbito de la robótica. Se puede considerar a un robot como “...una máquina, provista de cierta complejidad tanto en sus componentes como en su diseño o en su comportamiento, y que manipula información acerca de su entorno para así interactuar con él”. ${ }^{33}$ De acuerdo con la RAE, un robot es una “[m]áquina o ingenio electróni-

\footnotetext{
${ }^{28}$ Cfr. Bostrom, Nick, Superinteligencia...Op. Cit., p. 12.

${ }^{29}$ De acuerdo con Harari, uno de los problemas actuales es que se suele confundir a la inteligencia con la conciencia. Cfr. Harari, Yuval Noah, 21 lecciones... Op. Cit., pp. 91-92.

${ }^{30}$ Cfr. Damasio, Antonio, La sensación de lo que ocurre; cuerpo y emoción en la construcción de la conciencia, México, PAIDOS, 2019, pp. 202 y 311.

${ }^{31}$ Cfr. Íbidem, p. 317.

${ }^{32}$ Cfr. Monin, Maxim Aleksandrovich, Terekhova, Vera Albertovna y Ledeneva, Elena Vladimirovna, "The Chinese Room Argument in the context of the rational action theory." Utopia y Praxis Latinoamericana 25, Octubre 2020, pp.179-86. Disponible en: doi:10.5281/zenodo.3984228.

${ }_{33}$ Garcia-Prieto Cuesta, Juan "¿Qué es un robot?" en Barrio Andrés, Moisés, Derecho de los Robots, Madrid, Wolters Kluwer, 2a Edición, 2019.
} 
co programable que es capaz de manipular diversas operaciones", ${ }^{34}$ lo que lo hace estar relacionado con la posibilidad de programación de la IA.

En su relación con la IA, un robot puede realizar tareas más o menos complejas y automáticas. También puede o no tener una forma humana. Pero independientemente de la forma, entre más estrecha es la relación con la IA y por lo tanto más impredecible, el robot puede asemejarse más a un ser humano, sobre todo en los terrenos del libre albedrío o de la propia identidad, lo que hará cada vez más compleja la relación entre seres humanos y robots. Por estas características es por lo que, como veremos, esfuerzos jurídicos actuales consideran oportuno dotarlos en ciertas condiciones de una "personalidad jurídica electrónica”, con las implicaciones que esto puede tener para el terreno de los derechos. La pregunta, planteada entre otros por Llano Alonso en Homo Excelsior supone cuestionarse acerca de la posibilidad de agencia moral por parte de robots e incluso acerca de las razones que podrían justificar la misma. ${ }^{35}$

Cabe mencionar que el Parlamento Europeo sugirió, en una importante resolución del 16 de febrero de 2017 que a futuro será conveniente considerar a algunos robots -aquellos con un desarrollo tal que tomen decisiones autónomas- como personas electrónicas, sobre todo para efectos de la responsabilidad civil por daños que puedan cometer. ${ }^{36}$ Se hace patente de esta manera la inquietud general por considerar como una opción jurídicamente viable la catalogación de estos sistemas como titulares de derechos y deberes, derivados de una presunta "personalidad". Aún cuando se sugiere que de esto no se derivaría el hecho de que los robots puedan beneficiarse de "derechos humanos" sino únicamente dotarlos de un estatus similar al de las corporaciones para temas de responsabilidad, también hay voces que lo consideran inapropiado desde un perspectiva tanto ética como legal. ${ }^{37}$ Efectivamente, detrás de esta problemáti-

\footnotetext{
34 Diccionario de la Real Academia Española, voz "Robot", consultada el 7 de septiembre de 2020 en la página Web: $<$ https://dle.rae.es/robot>. El origen de la palabra "robot" viene directamente del inglés, pero se toma originalmente del checo "robota", que significa "trabajo". La palabra fue popularizada por el autor checo Karel $\square$ apek en el libro R.U.R. (Rossum's Universal Robots).

${ }_{35}$ Cfr. Llano Alonso, Fernando, Homo Excelsior. Los límites ético-jurídicos del transhumanismo, Tirant lo Blanch, 2018, pp. 152-3.

36 Resolución del Parlamento Europeo, de 16 de febrero de 2017, con recomendaciones destinadas a la Comisión sobre normas de Derecho civil sobre robótica (2015/2103(INL). <europarl.europa.eu/doceo/document/TA-8-20170051_ES.html>. 59. Pide a la Comisión que, cuando realice una evaluación de impacto de su futuro instrumento legislativo, explore, analice y considere las implicaciones de todas las posibles soluciones jurídicas, tales como:

f) crear a largo plazo una personalidad jurídica especifica para los robots, de forma que como mínimo los robots autónomos más complejos puedan ser considerados personas electrónicas responsables de reparar los daños que puedan causar, y posiblemente aplicar la personalidad electrónica a aquellos supuestos en los que los robots tomen decisiones autónomas inteligentes o interactúen con terceros de forma independiente.

${ }^{37}$ Cfr. Delcker, Janosch, "Europe divided over robot "Personhood", Politico, 11 abril 2018. Consultado en la dirección
} 
ca se encuentra terreno fértil para reflexionar en torno a la titularidad como al concepto y naturaleza filosófica de los derechos, especialmente los “humanos".

Sin embargo, de acuerdo con el Grupo Europeo sobre Ética de la Ciencia y las Nuevas Tecnologías, aunque algunos sistemas de IA pueden llegar a presentar capacidades intelectuales o cognitivas muy avanzadas, incluso superiores y entendidas como autónomas, en el sentido propio del término, el concepto de "autonomía" debe vincularse únicamente a los seres humanos y a su dignidad. La relación con la tecnología no debe de implicar, de acuerdo a este informe, un reconocimiento de derechos, sino un esfuerzo complejo por parte de la sociedad para determinar lo que es "bueno" y la forma de interacción con la tecnología. ${ }^{38}$

Por su parte, la Carta abierta a la Comisión Europea en temas de IA y robótica, firmada por más de 150 expertos en el tema, sostienen que la atribución de un estatuto jurídico de personas a máquinas, robots o sistemas de IA no debería fundarse ni en el modelo de la persona física, ni en el de la persona moral o jurídica. En el primero de los casos porque equiparar a estos sistemas a las personas físicas supondría atribuirles derechos humanos, lo que es esencialmente problemático; en el segundo caso porque admitiría reconocer que detrás de la acción de los robots habría intereses humanos, lo cual podría contradecirse con aquellos sistemas con capacidad de "autonomía" o "autoaprendizaje". ${ }^{9}$

El suponer o al menos plantear la posibilidad de reconocer una personalidad distinta a robots y sistemas de inteligencia artificial, con el efecto de dotarlos de un estatus jurídico que los haga acreedores de derechos y obligaciones es una preocupación en el fondo por lo "humano", que supone tanto el fundamento como la razón de ser de la existencia de estos derechos. Si ciertos atributos que en el futuro puedan tener estos sistemas los equiparará a "lo humano" de forma que una "personalidad completa" nos lleve a una era de "derechos post-humanos" ${ }^{40}$ o por el contrario, estas características deben situar a estas entidades con un estatus jurídico distinto, reservando estos derechos únicamente a los "seres humanos".

El problema planteado por esta postura conduce las reflexiones a los terrenos de la antropología filosófica. Específicamente, la distinción entre ser

\footnotetext{
URL: <https://www.politico.eu/article/europe-divided-over-robot-ai-artificial-intelligence-personhood/>

${ }^{38}$ Grupo Europeo sobre Ética de la Ciencia y las Nuevas Tecnologías. Declaración sobre Inteligencia artificial, robótica y sistemas "autónomos", Bruselas, 9 marzo 2018, Disponible en: <http://www.bioeticayderecho.ub.edu/archivos/ pdf/EGE_inteligencia-artificial.pdf>

${ }^{39}$ Cfr. Salardi, Silvia, "Robótica e Inteligencia...Op. Cit., p. 208. La "carta abierta" a la Comisión Europea se puede consultar en <http://www.robotics-openletter.eu/>.

${ }^{40} \mathrm{Cfr}$. Koops, Hildebrandt and Jaquet-Chiffell, "Bridging the Accountability Gap: Rights for New Entities in the Information Society?" Minnesota Journal of Law, Science \&t Technology, Vol. 11, No. 2 (2020), 497-561, 554.
} 
humano o individuo y persona. ${ }^{41}$ Parece que los enfoques actuales para la determinación de los fundamentos para reconocer titularidad de derechos humanos es que el sujeto cuente con la condición de "persona" más que la de miembro a la especie humana. Esta posición se conoce como "personismo", e implica la tarea de descubrir los rasgos que hacen que un ente pueda ser considerado como persona. Me parece que los esfuerzos por reconocer personalidad y derechos a robots se plasma en este tipo de reflexiones, igual que en el caso de reconocimiento de personalidad a empresas, ríos o animales.

De hecho, parece que el poder para dotar de "personalidad" a una determinada entidad, depende del sistema jurídico que tiene a su cargo definir quiénes son titulares de derechos y de obligaciones. Personas jurídicas, en este sentido, por definición no son seres humanos propiamente hablando, sino entidades que deben ser capaces de tener intereses (generalmente respaldados por seres humanos). En el fondo, la personalidad jurídica, de acuerdo con Solaiman supone que el ente pueda (i) ser sujeto de derecho, (ii) tener la posibilidad de "ejercer" derechos y deberes y (iii) disfrutar de derechos implica tener conciencia y libertad. ${ }^{42}$

Sin embargo, el reconocimiento de personalidad a una determinada entidad tiene como uno de sus principales objetivos el solucionar el problema de la responsabilidad por sus "actos”. Es por ello que la resolución del Parlamento Europeo antes referida propone la creación de un registro para robots. ${ }^{43} \mathrm{En}$ el fondo, la reflexión debe enfocarse en el problema de la autonomía; si un sistema de este tipo puede tener libertad para actuar de determinada manera ${ }^{44} \mathrm{y}$, en su momento, responder si un acto cometido por aquel supondría responsabilidad. De acuerdo con Fiordi, para asignar responsabilidad a un agente se requiere previamente el reconocimiento de un deber. Como los sistemas de IA o robots en principio no tienen una responsabilidad moral, en todo caso se podría hablar de que, al causar daños tendrían una responsabilidad objetiva o "accountability", donde el derecho tendrá que responder por los mecanismos de reparación. ${ }^{45}$

\footnotetext{
${ }^{41}$ Cfr. Ballesteros, Jesús, "Sergio Cotta y los retos del Siglo XXI." Persona y Derecho, no. 57, Diciembre 2007, pp. 71-79.

42 Cfr. Solaiman, S M. "Legal personality of robots, corporations, idols and chimpanzees: a quest for legitimacy" (2017) 25 (2) Artificial Intelligence and Law, University of Wollongong, 155-179.

${ }^{43}$ Cfr. Resolución (2015/2103(INL). <europarl.europa.eu/doceo/document/TA-8-2017-0051_ES.html>.

${ }^{44}$ Cfr. Salardi, Silvia, "Robótica e Inteligencia...Op. Cit., p. 221.

${ }^{45}$ Cfr. Dodig Crnkovic, Gordana, "Floridi's Information Ethics as Macro-Ethics and Info-Computational", Research Gate, 6 junio 2016, DOI: 10.1007/978-94-007-4292-5_1
} 
De cualquier modo, un par de ejemplos dejan abierta la posibilidad de la agencia moral por parte de estos sistemas y de esta forma abierta también la cuestión en torno a la personalidad de estos agentes. Así, Sparrow sostiene que un sistema de IA puede ser considerado persona por la constatación de su agencia moral. Y si los robots tienen cierta autonomía tienen también la posibilidad de actuar de mejor o peor manera, lo que los haría al menos en un primer plano responsables por sus acciones. Esto brinda la posibilidad de castigar la acción de un robot, pero supone que "matarlo" o desactivarlo sería en un primer momento "injusto", lo que implicaría que castigos "menos" severos puedan también ser injustos. De este razonamiento supone que una máquina que supere el test de Turing debe tener personalidad para juzgar la justicia 0 injusticia de las conductas que pongan en riesgo su existencia. ${ }^{46}$

Otro ejemplo lo expresa Guillermo Lariguet en un reciente artículo donde supone hipotéticamente, basándose en las reglas de Isaac Asimov, ${ }^{47}$ que un robot podría ser titular de derechos en tanto sea posible que tenga problemas al construir razonamientos prácticos, al igual que los seres humanos. Esto se manifestaría particularmente al interpretar las citadas reglas, lo que supondría que, si un robot puede discriminar y elegir entre dos posibilidades A o B, está ejerciendo su libertad pudiendo dañar a otro. Esto lo dota necesariamente de deberes y derechos morales. ${ }^{48} \mathrm{El}$ reconocer inteligencia y conciencia a estos sistemas los podría hacer "demasiado humanos" y, con ello, titulares de este tipo de derechos, lo que facilitaría el razonamiento práctico en caso de conflictos de intereses.

La sola posibilidad de imaginar una atribución de personalidad a sistemas de IA o robots, con el posible efecto del reconocimiento de ciertos derechos en algunos contextos, hace necesario realizar algunas reflexiones en torno a la teoría de los derechos humanos. Esto lo haremos en la siguiente sección; por

${ }^{46}$ Cfr. Sparrow, Rob, "Can machines be people? Reflections on the Turing Triage Test", en Lin, Patrick, Abney, Keith y Bekey, George A., Robot Ethics: The ethical and social implications of robotics, Massachusetts Institute of Technology, 2012, p. 305.

${ }^{47}$ Las reglas de los Robots de Asimov son las siguientes:

1. Un robot no puede dañar a un ser humano ni, por inacción, permitir que un ser humano sufra daño.

2. Un robot debe cumplir las órdenes de los seres humanos, excepto si dichas órdenes entran en conflicto con la Primera Ley.

3. Un robot debe proteger su propia existencia en la medida en que ello no entre en conflicto con la Primera o la Segunda Ley.

${ }^{48}$ El autor llega a estas conclusiones desde el análisis de dos cuentos de Isaac Asimov: "¿Qué es el hombre?" y "El hombre bicentenario". Cfr. Lariguet, Guillermo. "Humano, Demasiado Humano: ¿Podrian Tener Derechos Morales (Algunos) Robots? Un Análisis Filosófico a Partir De Dos Cuentos De Isaac Asimov". Principia luris 15, no. 28 (Julio 2017): 121 y 128. 
ahora podemos concluir este apartado junto con Roger Barta cuando dice que "[s]i se quiere imaginar máquinas cibernéticas que logran conquistar su libertad y autonomía, rompiendo las cadenas que las atan a los humanos, habrá que reflexionar antes sobre las condiciones que a nosotros nos permiten ser libres. Las máquinas, hasta hoy, constituyen un mundo completamente dominado por cadenas deterministas, salvo cuando sus inventores ejercen el libre albedrío que con dificultades han conseguido". ${ }^{49}$

\section{Hacia una teoría de los derechos humanos en el contexto de la Inteligencia Artificial}

Uno de los problemas más apremiantes de cualquier teoría de los derechos humanos es el de definir quiénes son titulares de los mismos y, por lo tanto, quiénes y ante quiénes se pueden reclamar estos derechos. ${ }^{50}$ Las respuestas que se den a esta pregunta son definitorias no sólo para la teoría, sino también para la práctica de los derechos humanos. Son comunes las discusiones en torno a si las colectividades, los niños, los no nacidos, los animales, las generaciones futuras, las corporaciones e incluso los robots son o pueden ser titulares de estos derechos, y las implicaciones que esto tendría. ${ }^{51}$

Es importante también preguntarse por los derechos que una determinada entidad puede reclamar, así como por las razones que justifican la atribución de un "derecho humano" a su titular y el por qué puede reclamarlo. En la fórmula básica de un derecho humano como derecho subjetivo presentada por Alan Gewirth, donde $A$ tiene un derecho a $X$ exigible a $B$, por virtud de $Y,{ }^{52} \mathrm{el}$ reto que se presenta es definir quién puede ser $A$, así como los derechos " $x$ " que puede reclamar, ante quién y por qué. ${ }^{33}$ De acuerdo con James Dawes, la pregunta en el fondo podría también ser planteada en el sentido de averiguar qué significado tendrá para los derechos humanos el hecho de que la inteligencia artificial trascienda la humana. ${ }^{54}$ Las implicaciones de esta pregunta para los

\footnotetext{
49 Bartra, Roger, Cerebro y Libertad. Ensayo sobre la moral, el juego y el determinismo. México, Fondo de Cultura Económica, 2017, pp. 153-154.

${ }^{50}$ Waldron, Jeremy, Law and Disagreement, Oxford University Press, 1999, p. 226.

51 Íbid. Véase también, Ramírez Garcia, Hugo Saúl y Pallares Yabur, Pedro de Jesús, Derechos Humanos, México, Oxford University Press, 2011, pp. 75-86.

${ }^{52}$ Cfr. Gewirth, Alan, The Community of Rights, Chicago, The University of Chicago Press, 1996, pp. 8-9.

${ }_{53}$ Es importante preguntarse siempre por los porqués de los derechos humanos porque de lo contrario se corre el riesgo de verlos como una retórica vacía. Cfr. Fagan, Andrew, Human Rights; Confronting Myths and Misunderstandings, Camberley, Edward Elgar, 2009: p. 145.

${ }^{54}$ Dawes formula la pregunta de la siguiente manera: "What will it mean for human rights when artificial intelligence trascends the human?". Cfr. Dawes, James, "Speculative Human Rights", en Human Rights Quarterly, Volume
} 
derechos humanos pueden tener efectos tanto para la titularidad como para las posibles afectaciones en la exigencia de estos derechos.

Hay que considerar, dentro de este contexto, que los derechos humanos se han vuelto un paradigma ético actual, que parece que convierten cualquier acción en buena. A esto Francesco Viola lo ha llamado la "ética de los derechos", 55 quizá una explicación para comprender el amplio uso de este lenguaje en la actualidad. Sin embargo, el extendido uso de los mismos ha hecho que exista una inflación de derechos, que quieren utilizarse para prácticamente cualquier circunstancia, incluida una ética para los robots, con el riesgo de que los mismos pierdan valor, tal como en una inflación monetaria. ${ }^{56}$

Si bien los derechos humanos se basan en valores, también lo hacen en necesidades radicales de los seres humanos, entendidas como aquellas que, de no cumplirse, generan un daño grave, ya sea individual o social. Pero en este caso, también es necesario poder dialogar acerca de los criterios que hacen a una necesidad real o verdadera o falsa. ${ }^{57}$ Esto nos lleva al tema de la autenticidad de los derechos humanos, no sólo en su formulación normativa, sino también interpretativa. En trabajos previos -siguiendo a Sergio Cotta-, hemos sostenido que la autenticidad de los derechos humanos debe enfocarse en el ámbito coexistencial del ser humano, reconociendo su ontología y características propias, así como en los valores que sostienen estos derechos, su perdurabilidad en el tiempo, así como una vinculación entre libertad y responsabilidad. ${ }^{58}$

Sin embargo, más allá de la cuestión de si tienen o deben tener derechos los robots, qué derechos "tendrían” y cómo estarían fundamentados, me parece que debemos considerar, junto con Freeman, que los derechos no son "cosas" que se

\footnotetext{
42, Number 3, August 2020, p. 575 Disponible en: D0I: 10.1353/hrq.2020.0033.

${ }_{55}$ Una ética de los derechos es "aquella ética en la que los derechos son el valor prioritario y dominante, y en la que, por tanto, la cuestión fundamental no consiste en establecer si una acción es buena o debida, sino si se tiene o no el derecho a realizarla". Cfr. Viola, Francesco, "La ética de los derechos", en Doxa, núm. 22, 1999, p. 507.

${ }^{56}$ De acuerdo con Francesco Carnelutti, "Los efectos de esta inflación legislativa [y podemos adaptarlo a lo que ahora analizamos: de los derechos humanos] son los mismos que los de la inflación monetaria, la desvalorización; en nuestro caso, la pérdida de valor del Derecho, de la certeza y de la propia racionalidad...". Prieto Sanchis, Luis. El constitucionalismo de los derechos; Ensayos de filosofía jurídica. Madrid, Editorial Trotta, 2013, p. 183. Se le atribuye a Franceso Carnelutti la comparación entre las dos realidades. Efectivamente, dice él que ".... los inconvenientes de la inflación legislativa no son menores que los debidos a la inflación monetaria: son como todos saben, los inconvenientes de la desvaloración". Carnelutti, Francesco. Cómo nace el derecho. Bogotá, Editorial Temis, 2010, p. 55.

${ }^{57}$ Cfr. Rodríguez Palop, María Eugenia, Claves para entender los nuevos derechos humanos, Madrid, Catarata, 2011, pp. 33-36.

${ }_{58}$ Cfr. Ramírez-Garcia, Hugo Saúl y Díez Spelz, Juan Francisco, La autenticidad y el fundamento de los derechos humanos. Una aproximación desde la filosofía jurídica de Sergio Cotta. Madrid, Universidad Complutense de Madrid, 2016, pp. 185-203.
} 
tienen, ${ }^{59}$ sino títulos que pueden reclamarse y sobre los cuales alguna entidad tendrá deberes para respetar y protegerlos. Por eso, ante temas límites como el que nos atañe, la labor intelectual debe enfocarse en la justificación y fundamentación de los mismos. De acuerdo con Jeremy Waldron, puede sostenerse que se "tiene" un derecho, o que alguien es titular de los mismos, cuando se constata un interés por parte del titular que está suficientemente fundado como para atribuirle un deber a otro. En el caso de los individuos humanos, la existencia de intereses o necesidades suficientes para fundamentar un "derecho" es un tema en general aceptado. ${ }^{60} \mathrm{El}$ problema se presenta con otro tipo de entes.

En este sentido, la distinción ontológica entre distintos entes para la atribución de derechos se vuelve apremiante. Como adelantábamos al final de la sección anterior, las dudas o problemas límites entre la atribución de "personalidad" o "derechos" a un ente, está relacionada con la posibilidad de agencia moral y, sobre todo, con la calidad de deberes y de trato que se les debe de dar precisamente por dicha agencia, fincada ya sea en valores como la dignidad o la libertad. De cualquier forma, en el caso particular de robots o sistemas de IA, la cuestión, siguiendo a Gunkel, se refiere no sólo a si los mismos tienen derechos, sino a "si" deben tenerlos. ${ }^{61}$

La consideración planteada por Gunkel vuelve el tema un asunto no tanto ontológico, sino deontológico y traslada el objeto de nuestra reflexión al análisis hipotético. De acuerdo de nuevo con Dawes, el terreno hipotético o de experimentación mental en el que nos encontramos puede hacernos hablar de "derechos especulativos”, basados en cuestiones de razón, y no de tradición. ${ }^{62} \mathrm{De}$ esta manera, ante los esfuerzos apuntados que pretenden otorgar personalidad y, por lo tanto, posiblemente derechos, a entidades como robots o sistemas de IA, debemos preguntarnos qué implicaría que alguna de estas entidades tuviera "derechos", y qué conductas o deberes se desprenderían de este hecho para otros, específicamente otros humanos, corporaciones, autoridades o instituciones. Por ahora, me parece que la intuición que genera la cuestión permanece en el terreno de las preguntas y las hipótesis, pero vale la pena considerarla, ante los efectos que pudiera tener, y de hecho ya tiene, la tecnología en la vida de los seres humanos.

\footnotetext{
${ }_{59}$ Cfr. Freeman, Michael, Human Rights, Cambridge, Polity, Third Edition, 2017: p. 7.

${ }^{60}$ Cfr. Waldron, Jeremy, "Rights and Human Rights", en Tasioulas, J. (Ed)., The Cambridge Companion to The Philosophy of Law, Cambridge, 2020, p. 152.

${ }_{61}$ Gunkel, David J., "The other question: can and should robots have rights?", en Ethics Inf Technol, 20, 2018, pp. 87-99.

${ }^{62}$ Cfr. Dawes, James, "Speculative... Op. Cit., pp. 575-576.
} 
De cualquier modo, debemos ser cuidadosos con el lenguaje y lo que implica. En otras palabras, es una invitación a continuar la reflexión en torno a lo que significa "tener" o "ser titular" de cualquier derecho y a las posibles implicaciones de una inflación de los mismos al usarse en cualquier circunstancia. Por ejemplo, Patrick Hopkins, analizando un presunto derecho a la mejora de los seres humanos (o human enhancement) en el contexto del transhumanismo, es consciente del riesgo que se corre al pretender utilizar este lenguaje para cualquier situación. Incluso sostiene que sería de gran ayuda un "detector de derechos", pero al no ser el caso, la tarea del jurista debe centrarse en justificar y fundamentarlos al caso concreto. ${ }^{63}$

En principio, decir que uno tiene un derecho, o que es titular de mismo, significa expresar un juicio acerca de la legitimidad de un acto dentro del contexto social o la necesidad de satisfacer ciertos intereses. ${ }^{64}$ Este juicio supone un compromiso moral hacia los titulares de los mismos, por considerarlos como seres dignos que merecen un reconocimiento y determinado trato. También pueden entenderse los mismos como las condiciones que hacen posible que una sociedad sea justa. ${ }^{65}$ Pero en cualquiera de los casos, fundamentados en la dignidad del sujeto que puede reclamarlos.

$\mathrm{Al}$ parecer, la realización de estas exigencias se complica para el caso de los robots y sistemas de IA. Si pensamos en la dignidad humana como fundamento intrínseco de los derechos humanos, parte del razonamiento que ya hemos iniciado debe enfocarse en la determinación del estatus que la IA podría tener a futuro -o que incluso tiene hoy en día a través de diversos medios-; si como mera herramienta o instrumento, o con la posibilidad de interactuar de tal manera con los humanos que en su coexistencia se haga necesario un otorgamiento de cierta "dignidad", aunque sea graduada,${ }^{66}$ derivada de una posible "singularidad" o "individualidad" detectable para cada sistema.

63 Hopkins plantea en este artículo que tradicionalmente la teoria de los derechos humanos ha enfocado sus esfuerzos en fundamentarlos ya sea en el derecho natural, en la autonomía o en los intereses del sujeto. Cfr. Hopkins, Patrick, "Is Enhancement worthy of being a right?", en More, Max y Vita-More, Natasha, The transhumanist reader, Oxford, Wiley-Blackwell, 2013. Véase también Agar, Nicholas, Truly human enhancement; A philosophical defense of Limits, Londres. The MIT Press, 2014, p. 347.

64 Rodríguez Puerto, M. J. y Robles, G., "Algunas precisiones en torno a los derechos humanos", en Megías Quirós, José Justo, Manual de Derechos Humanos: Ios derechos humanos en el siglo XXI, Thomson Aranzdi, 2006, p. 24.

${ }^{65}$ Cfr. Weston, Burns H, "Human Rights: Concept and Content", in Weston, Burns H., and Grear, Anna, Human Rights in the World Community; Issues and Action, University of Pennsylvania Press 2016: p. 7.

66 De acuerdo con Menke, la dignidad puede entenderse de cuatro maneras distintas: 1) Dignidad dada y sin gradaciones, 2) Dignidad dada y con gradaciones, 3) Dignidad adquirida sin gradaciones y 4) Dignidad adquirida con gradaciones. Si los seres humanos tenemos de acuerdo con él una dignidad dada y con gradaciones, surge la pregunta de si alguna otra entidad pudiera estar dotada de algún otro tipo de dignidad. Cfr. Meneke, Christoph y 
Si bien la dignidad humana es un atributo de los seres humanos, que podemos aceptar en principio que se posee por el mero hecho de serlo, y que de la misma derivan ciertas exigencias prácticas de comportamiento que se van desarrollando -una dignidad dada y con posibles gradaciones- ${ }^{67}$ la reflexión en torno al otorgamiento de "personalidad jurídica electrónica" a algunos entes tendría que preguntarse si lo mismo implicaría un otorgamiento también de cierta "dignidad" como fundamento de una determinada expectativa de trato en el marco de sus acciones, tanto en el posible terreno de los derechos humanos como en el de la responsabilidad. En este sentido sería preguntarse si puede haber otro tipo de "dignidades", como lo intuye Etinson en un reciente artículo. ${ }^{68}$

Cierto es que el fenómeno de la dignidad, y sobre todo el de sus implicaciones, es complejo. Etinson incluso reconoce que una teoría acerca de la misma tiene al menos que contemplar la cuestión acerca de su naturaleza, de sus requerimientos prácticos, aspectos metodológicos y, sobre todo, las exigencias prácticas que se desprenden de la misma. ${ }^{69}$ Por otro lado, autores como Laura Valentini propugnan por desvincular el concepto de dignidad del de humanidad, sosteniendo que la misma no es inherente, sino que depende de un status al que al menos, aún cuando la autora no lo contempla, pueda reconocérsele a entes dotados de personalidad, como el que analizamos. ${ }^{70}$

Aunque personalmente me inclino por pensar que la dignidad es una característica inherente a los seres humanos; un aspecto dado y graduado, como sugiere Menke, y que puede entenderse como valor social, principio o incluso como un derecho, ${ }^{71}$ no debemos desdeñar por ese motivo la pregunta en torno al status de creaciones humanas como la IA o los robots, sobre todo por la capacidad que tienen o tendrían de emular ciertas acciones humanas. Pero no sólo eso, sino que considero que la pregunta es pertinente por la coexistencia o vinculación con los seres humanos, es decir, que la cuestión de su estado o de su personalidad incluso se justificaría de manera derivada, sin perder de vista lo humano. Al menos ese debería ser uno de sus objetivos y será tratado en el siguiente apartado.

\footnotetext{
Pollmann, Arnd, Filosofía de los Derechos Humanos, Barcelona, Herder, 2010, pp. 147-149.

${ }^{67}$ Cfr. İbid.

${ }^{68}$ Cfr. Etinson, Adam, "What's So Special About Human Dignity?", en Philosophy \&t Public Affairs 48, no. 4, 2020, p. 372.

${ }^{69}$ Cfr. Íbidem, p. 356.

${ }^{70}$ Cfr. Valentini, Laura, Dignity an, d Human Rights: A Reconceptualisation, Oxford Journal of Legal Studies, Vol. 37, No. 4, 2017, pp. 862-885, Disponible en: doi:10.1093/ojls/gqx011.

${ }^{71}$ Cfr. Barak, Aharon, Human Dignity: The Constitutional Value and the Constitutional Right, Cambridge University Press, 2015.
} 
La discusión actual no debe olvidar estos supuestos, ni dar por sentada la "normalidad" de los derechos humanos para ser atribuidos a distintos entes. Es, como hemos sostenido, un problema al fin y al cabo de justificación que debe preguntarse por las razones de lo jurídico. Sin duda actualmente, sobre todo pensando en el tema de la responsabilidad, podemos sugerir que son los fabricantes, diseñadores o incluso los usuarios quienes tendrán que responder por acciones nocivas atribuibles a un sistema algorítmico, pero a futuro, si el artefacto comienza a funcionar sin guía humana, o incluso "superando lo humano", la clave de la responsabilidad y por lo tanto de los derechos no se vuelve tan clara. ${ }^{72}$

En este sentido, el mismo Parlamento Europeo, aparte de sugerir la creación de un estatuto de la persona electrónica, también propone la creación de un código de conducta ético voluntario que regule los impactos sociales, ambientales y de salud humana de la robótica, y que asegure que operen de acuerdo a derecho, contando con un botón de desconexión para casos de emergencia, así como la creación de un registro para robots inteligentes. ${ }^{73}$ En ese contexto, los derechos humanos o fundamentales, así como los principios de no maleficencia, beneficencia, autonomía y justicia deben ser el marco de actuación para la reflexión ética en torno al papel que jugarán los robots en un futuro. ${ }^{74}$

La Declaración de Toronto del año 2018 también hace patente el riesgo que pueden correr los derechos humanos en contextos de interacción entre sistemas de IA con seres humanos. En particular, los problemas pueden presentarse por el machine learning, o capacidad de las máquinas de aprender y volverse, más que meros "instrumentos", herramientas imprevisibles para los humanos. Esto puede llevar por un lado a problemas de discriminación, cuando las máquinas operen sus algoritmos de manera que una víctima humana se vea afectada. Otro problema surge de la opacidad de la actividad de una máquina. El no saber cómo se tomaron las decisiones que nos afectan, por parte de sistemas de IA, hace complicado un sistema de responsabilidad. Por eso, en contextos de interacción, la preocupación consiste en que los robots no violen derechos humanos tanto nuestros, como de generaciones futuras, pero también evaluando las exigencias dentro de estos contextos de interacción. ${ }^{75}$

\footnotetext{
72 Cfr. Froomkin, A. Michel, "Prólogo"...Op. Cit.

73 Resolución del Parlamento Europeo, de 16 de febrero de 2017, con recomendaciones destinadas a la Comisión sobre normas de Derecho civil sobre robótica (2015/2103(INL)), 59. <europarl.europa.eu/doceo/document/TA-82017-0051_ES.html>.

74 İbidem, 13, 66 y Anexo. Véase también Barrio Andrés, Moisés, "Robótica, inteligencia artificial y Derecho", en ARI $103 / 2018$ - 7/9/2018, p. 5.

75 Cfr. The Toronto Declaration: Protecting the right to equality and non-discrimination in machine learning systems, Disponible en: <https://www.accessnow.org/cms/assets/uploads/2018/08/The-Toronto Declaration_ENG_08-2018.pdf>
} 
Destaca en estos supuestos la posibilidad de contemplar algoritmos como sujetos activos de probables violaciones a derechos humanos. A esto Ureña lo ha llamado recientemente "autoridad algorítmica", indicando que,

“...los procesos de decisión autónomos se usan en ocasiones para cumplir funciones estatales, o son usados por particulares de forma tal que pueden poner en riesgo los derechos humanos. En estos dos casos, estamos ante el ejercicio de una verdadera autoridad algorítmica, que tiene, al menos, cuatro características: es "autoridad", pues se trata de un ejercicio de la capacidad de determinar, mediante el uso de algoritmos, el comportamiento de un individuo o entidad" ${ }^{76}$

En cualquier caso, independientemente de la atribución o no de derechos a sistemas de IA o robótica, así como la detección de sus responsabilidades en la materia, es importante contemplar que es un fenómeno que se debe considerar cuando pensamos en personas y personalidad. De cualquier modo, de acuerdo con Jesús Ignacio Martínez, los derechos humanos son categorías a través de las cuales pensamos, y definen la forma en la que interactuamos actualmente y en el futuro. ${ }^{77}$ Considerando así a los derechos humanos, estos se configuran como los parámetros de validez y justicia de las distintas acciones humanas -Martínez los considera por eso como la "conciencia” del derecho.- En este sentido, deben ser utilizados como esquemas mentales para transformar, crear y diseñar los algoritmos, pero también para planear la interacción entre el ser humano y la máquina inteligente, poniendo a la persona en primer plano, tanto a la que está detrás del algoritmo, como los programadores, inversores, diseñadores, como a los usuarios o posibles personas que se vean afectadas por las acciones de la IA. ${ }^{78}$ Los derechos humanos, como títulos y criterios de justicia, deben estar detrás de todas estas interacciones.

\section{Lo humano y lo no-humano: hacia una reflexión en torno a robots y derechos humanos}

Después de haber realizado estas reflexiones en torno a los derechos humanos y los sistemas de IA o robots, considero que la problemática de fondo se

\footnotetext{
${ }^{76}$ Cfr. Urueña, René, "Autoridad Algorítmica: ¿cómo empezar a pensar la protección de los derechos humanos en la era del 'Big Data'?" en Latin American Law Review, no. 2, enero 2019, p. 105.

${ }_{77}$ Cfr. Martinez García, Jesús Ignacio, "Inteligencia y derechos humanos en la sociedad digital", en Cuadernos Electrónicos de Filosofía del Derecho, Número 40, 2019, p. 176.

${ }^{78}$ Cfr. Íbidem, pp. 185-6.
} 
inscribe en la distinción entre aquello que es humano y lo no-humano. El término "humano" en sus orígenes hace referencia a la tierra o terrenal, en oposición a lo divino o a lo animal. ${ }^{79}$ Repensar lo humano en este contexto perfila la problemática de cómo nos comprendemos como miembros de la especie, frente a otros seres como los sistemas que analizamos en este estudio. Este contraste me parece está en juego cuando nos entendemos no sólo frente a lo animal o las cosas, sino ante seres o sistemas que nos impresionan por su capacidad creada y que cuestionan hasta cierto punto el mismo concepto de humanidad. En definitiva, la categoría de humano no se puede entender si no se pone en conexión con lo no-humano. ${ }^{80}$

Aparentemente, nuestras capacidades únicas nos marcan y definen, otorgando una especial dignidad, que parece que se puede confrontar con la de otros entes. ${ }^{81}$ En cuanto a los derechos que se desprenden de esta categoría, como lo apunta también Martínez, hay que tomar en cuenta que los mismos surgieron precisamente de la confrontación entre lo humano y lo inhumano -la barbarie, la injusticia, el desprecio y habría que agregar que por fenómenos como la esclavitud o las masacres- y que ahora se nos abre otro frente con lo "no humano", en la interacción con la IA.$^{82}$ Posiblemente, podríamos decir, es de los mayores retos para el concepto de derechos humanos, porque comprendemos que esta interacción puede ser objeto de confusiones entre lo que es verdaderamente humano y lo que no.

En este tema, Moisés Barrio Andrés analiza qué tanto, y hasta qué punto, una posible "nueva categoría" de sujeto jurídico como la probablemente atribuible a entes no-humanos puede ser "titular" de ciertas exigencias o expectativas. En todo caso, el problema se materializa en el tema de una "atribución de status”, que puede ser en estos casos incompleta, contextual e incluso inestable $u$ oportunista. ${ }^{83}$ De acuerdo con este mismo autor,

“...la personalidad electrónica -que no persona electrónica- puede ser reputada como un enfoque plausible al problema, tanto para los robots dotados de un cuerpo como para los robots software que exhiben un cierto grado de autonomía e interactúan con las personas, en cuanto

\footnotetext{
79 Cfr. Mancosu, Paola, "Repensar lo humano. Aproximaciones post-dualistas a la obra de Gamaliel Churata", en Bulletin of Hispanic Studies, 97, no. 8, septiembre 2020: 859-69, doi:10.3828/bhs.2020.49.

${ }^{80}$ Cfr. Íbidem, p. 866.

${ }^{81}$ Cfr. Etinson, Adam, "What's So Special...Op. Cit., p. 354.

${ }^{82}$ Cfr. Cfr. Martínez García, Jesús Ignacio, "Inteligencia y derechos humanos...Op. Cit., pp. 178-180.

${ }^{83}$ Cfr. Barrio Andrés, Moisés, "Hacia una personalidad electrónica para los robots", en Revista de Derecho Privado, no. 2, marzo 2018, p. 103.
} 
que tendrían la posibilidad de ser titulares de relaciones jurídicas con sus correspondientes derechos y obligaciones, y tener un cierto reconocimiento jurídico de su subjetividad, fundamentalmente en derechos de naturaleza patrimonial, pero no los constitucionales ni los de la personalidad, absolutamente consustanciales a la dignidad de los seres humanos tal y como recuerdan textos internacionales recientes como la Declaración universal de la UNESCO sobre bioética y derechos humanos de 2005 o la Carta de los Derechos Fundamentales de la Unión Europea de 2000". ${ }^{84}$

En este caso, una "personalidad" -que no persona, hay que enfatizar- reconocida a entes "no-humanos" podría de acuerdo con el autor ser un fundamento suficiente para la atribución de ciertos derechos, pero no de aquellos "humanos", sino solo los "patrimoniales". Esto nos lleva de nuevo a la consideración de la dignidad como algo propiamente "humano". Si bien, pensando en la "persona" más que en la "personalidad", aun cuando todos los seres tienen un determinado valor, la relación entre lo humano y lo no-humano nos debe de permitir repensar lo que verdaderamente significa ser lo primero. ${ }^{85}$ De cualquier manera, me parece que el rescate de lo humano consiste no únicamente con reconocer la naturaleza racional del ser humano, sino otros aspectos que son esenciales, como su capacidad de relación, su limitación, su finitud y la consciencia que tenemos de nuestra propia imperfección e indigencia. ${ }^{86}$

De esta forma, preguntas acerca del desarrollo moral de algoritmos y máquinas, nos compele a pensar profundamente en los aspectos en los que como humanos nos parecemos a las mismas y lo que nos distingue y otorga un determinado estatus moral y jurídico. ${ }^{87}$ También implica reflexionar en torno a la interacción social con robots, pues no sabemos si será "social” en el mismo sentido que con seres humanos. ${ }^{88}$ Esta interacción se volverá mayor, de acuerdo con Hakli, en cuanto conceptos como obligación, responsabilidad y compromiso se integren en las relaciones mutuas entre distintos entes. ${ }^{89}$ Estos conceptos

\footnotetext{
84 Íbidem, p. 105.

${ }^{85}$ Cfr. Palacios, Leopoldo-Eulogio, "La persona humana", Verbo, núm. 495-496 (2011), p. 407.

${ }^{86}$ Estos elementos se toman de la propuesta antropológica de Sergio Cotta. Para él, estas características son definitorias del ser humanos. Cfr. Cotta, Sergio. II diritto nell'esistenza; Linee di ontofenomenologia giuridica. Milano, Giuffré Editore, Seconda edizione, 1991, passim.

${ }^{87}$ Cfr. Wallach, Wendell Arnhold, "Moral Machines and Human Ethics ", en J. Seibt et al. (Eds.), Sociable Robots and the Future of Social Relations, IOS Press, 2014, p. 19.

${ }^{88}$ Cfr. Hakli, Raul, "Social Robots and Social Interaction", en J. Seibt et al. (Eds.), Sociable Robots and the Future of Social Relations, IOS Press, 2014, p. 105.

${ }^{89}$ Cfr. Íbidem, p. 106.
} 
normativos parece que serán reflejo de interacciones que podrían hacer necesario que los mismos se traduzcan en derechos y obligaciones.

Así, Travieso es puntual al afirmar que parece que se ha dejado ya el humanismo tradicional, pues los agentes no humanos han adquirido cada vez mayor relevancia y la interacción entre lo humano y lo no humano transforma las ideas que tenemos acerca de la vida en sociedad y, por supuesto, el derecho. ${ }^{90}$

Las reflexiones en torno al replanteamiento de este humanismo tradicional, a la relación entre lo humano y lo no-humano, deberán dirigirse también al contexto del transhumanismo, donde se apuesta por la mejora de la condición humana por la hibridación entre la naturaleza humana y aquella de la inteligencia artificial. ${ }^{91}$ Esto supone el riesgo de producir desigualdad social entre aquellos que pueden acudir a estas "mejoras" y aquellos que no, lo que en palabras de Campione puede provocar la deshumanización de la especie, al acudir a conceptos como el de una "dignidad posthumana"92 a la que no todos puedan acceder y que, me parece, iría en contra del concepto mismo de dignidad o al menos al de igualdad entre personas que puedan o no acceder a estos avances. Recuerda esto a los retos que se han planteado desde siempre acerca de la teoría de los derechos humanos donde no todos han sido siempre reconocidos como titulares de los mismos, como reconoce Waldron. ${ }^{93}$

Parecería que, en un horizonte posthumanista donde cuasimáquinas, o cuasihumanos convivan entre ellos, será necesario preguntarse por lo que queda del ser humano como tal. En este sentido, la reflexión deberá tomar en cuenta aspectos antropológicos relevantes, incluso bioéticos, que permitan comprender los orígenes y consecuencias de pretender crear un hombre robótico, sólo por la posibilidad tecnológica de realizarlo. ${ }^{94}$ Como decíamos anteriormente, justamente por estas razones, el problema que se tiene en frente es de naturaleza eminentemente moral, que debe encauzar la ciencia y el progreso hacia la obtención de auténticos beneficios, que tengan como base tanto

${ }^{90}$ En este contexto, dice Travieso que "Esta es una característica del sujeto posmoderno: la transferencia de la razón fuera del cuerpo humano e incluso su superación, pues algunas máquinas pueden superar la racionalidad humana en el procesamiento de datos". Cfr. Travieso, Juan Antonio, "Las personas jurídicas en el nuevo derecho y tecnología. Bienvenidos los robots", en Bielli, Gaston E., Mora, Santiago J. y Fernández, Diego (Dirs.), \#LegalTech II. El Derecho ante la tecnología, Thomson Reuters, 2019, pp. 83-85.

${ }^{91}$ Cfr. Campione, Roger, "A vueltas con el Transhumanismo: cuestiones de futuro imperfecto", Cuadernos Electrónicos de Filosofía del Derecho, Número 40, 2019, p. 46

92 Cfr. Íbidem, p. 63.

${ }_{93}$ Cfr. Waldron, Jeremy, "Rights and Human...Op. Cit., p. 160.

94 Cfr. Pichardo, Luz Maria, "Reinventing Bioethics in a Post-humanist and Post-truth Society. The Present and Future of Bioethics", en Pers. Bioét. 2018; 22(2): 212-222. 
lo universal como lo particular y variable de la dignidad humana manifestada en distintas culturas. ${ }^{95}$

Sólo un ente dotado de esa "dignidad humana" es titular de derechos "humanos", pues esto fundamenta la inclusión del término "humano" en el concepto. De este modo, siguiendo implícitamente a Aharon Barak, sostengo que entes sin dignidad no pueden tener propiamente derechos "humanos", aunque posiblemente sí lleguen a ejercer otro tipo de derechos, ${ }^{96}$ como ya se planteaba. Analizando la película de Blade Runner, Javier de Lucas defiende que los seres humanos somos y debemos seguir siendo los "dueños del tiempo" y del derecho. ${ }^{97}$ Pero al fin y al cabo, el encuentro con el otro, el reconocer la diferencia, e incluso aquello que es "auténticamente humano", incluso en otras realidades, nos debe interpelar para actuar de acuerdo a las exigencias de la dignidad, es decir, a humanizarnos en el proceso. ${ }^{98}$

Como intuye Rafael de Asís Roig, el problema de los derechos humanos surge cuando existen ciertas decisiones que se proyectan sobre los derechos de otros, lo que hace indispensable identificar a los titulares de los mismos y los intereses que entran en conflicto. Esto requiere repensar el problema de la autonomía, responsabilidad, integridad humana y la definición de los actos contrarios a los derechos que se pueden manifestar ante nuevos retos o amenazas y las formas de resolverlos. ${ }^{99}$ Así, aún cuando no se deriven derechos humanos propiamente hablando de la "naturaleza robótica", pueden encontrarse ciertos elementos que vinculen a la dignidad humana y que, sobre todo por la posibilidad de entrar en conflicto con derechos de humanos, sea necesario en casos concretos acudir a solucionar estos conflictos entre los mismos, poniendo prioridad en lo humano.

Dar prioridad a lo humano requiere invertir en una inteligencia colectiva más intensa, que potencie y redescubra lo humano, con aspiraciones universales, es decir, no únicamente mirando a una perspectiva occidental, sino

\footnotetext{
${ }^{95}$ Cfr. Ibidem, p. 221.

${ }_{96}$ Barak postula esta idea al analizar si las corporaciones pueden o no ser titulares de derechos. Menciona que, aun cuando pueden ejercer ciertos derechos, el no poseer ontológicamente dignidad significa que estos no pueden ser derechos "humanos". Cfr. Barak, Aharon, Human Dignity...0p. Cit.

${ }^{97}$ Cfr. De Lucas, Javier, Blade Runner; El Derecho, guardián de la diferencia, México, Tirant lo Blanch, 2012, p. 31.

${ }^{98}$ Cfr. İbidem, pp. 32-33. Blade Runner, ya sea que se traduzca como "el que corre con la espada" o "el que camina sobre el filo" (Guarner), puede ser un ejemplo de encuentro con el otro; de percatarnos que lo humano se construye y que, en la interacción entre seres, siempre existe la posibilidad tanto de humanizarse como de deshumanizarse. ${ }_{99}$ Cfr. MCmillan, Marianna., "Una mirada a la robótica desde los derechos humanos", Persona y Derecho, no. 79, Julio 2018, p. 264. Ver también de Asís, Rafael., Una mirada a la robótica desde los derechos humanos, Madrid, Dykinson, 2015.
} 
transcultural y trans-temporal, que se proyecte hacia generaciones futuras. ${ }^{100}$ La clave que parece que vamos descubriendo, aunque haga falta repensarla constantemente, es la tarea de definir lo humano como algo tanto dado, como construido, que se proyecta en las relaciones que sostenemos con los otros o con "lo" otro.

En su reciente libro The Game, Alessandro Baricco concluye que esta época de avances tecnológicos, que nos presenta retos que hemos ya descrito, requiere que los seres humanos se sigan sintiendo humanos. Y sostiene que "[e] $\mathrm{n}$ los próximos cien años, mientras que la inteligencia artificial nos llevará más lejos de nosotros, no habrá bien más valioso que todo lo que haga sentirse seres humanos a las personas. Por muy absurdo que pueda parecernos ahora, la necesidad más extendida será la de salvar una identidad de la especie. En ese momento recogeremos lo que hayamos sembrado en estos años”. ${ }^{101}$

\section{Conclusión}

El tema analizado en este artículo es, sin duda, una cuestión límite. Los distintos elementos que hemos estudiado no pretenden dar una respuesta absoluta al problema en torno al reconocimiento de una posible "personalidad jurídica" a robots o sistemas de IA y, con ello, de una probable atribución de "derechos humanos" o derechos en general a estas entidades. En cualquier caso, hemos intentado demostrar que los avances tecnológicos suponen un reto ineludible tanto para el derecho en general como para la comprensión de la naturaleza de los derechos humanos. Como lo reitera Llano Alonso, este contexto tecnológico también cuestiona valores como la dignidad, libertad, identidad, autonomía o voluntad. ${ }^{102}$

Las fronteras del desarrollo tecnológico, independientemente de los efectos que se plantean de reconocimiento de personalidad o de derechos, me parece que nos deben transportar a la reflexión en torno a lo humano y lo no-humano. Más allá de la naturaleza de un ente en específico, las exigencias de los derechos "humanos" deberían sentar las bases para la humanización de las acciones, tanto de los seres humanos, quienes pueden actuar o no de acuerdo con su naturaleza, como la de otros entes cuya interacción incluso "moral” pueda tener efectos en lo que es propiamente humano. Los esfuerzos tanto

\footnotetext{
100 Cfr. Zamarriego, Laura, "El hombre y la máquina", en ethic, Disponible en: https://ethic.es/2019/01/tecnologia-y-etica-era-maquinas/

101 Baricco, Alessando, The Game, Anagrama, 2019, p. 330.

102 Cfr. Llano Alonso, Fernando, Homo Excelsior...0p. Cit., p. 16.
} 
teóricos como prácticos de considerar estas posibilidades deben de re-cuestionarse constantemente tanto la naturaleza como los propósitos de los "derechos" y también de los distintos agentes que participan en el contexto práctico. Por el momento, estas exigencias se concretan en diseñadores, programadores o usuarios, pero no podemos descartar y desatender el papel que sistemas de IA o robots tienen y tendrán a futuro en este contexto.

\section{Bibliografía}

Agar, Nicholas, Truly human enhancement; A philosophical defense of Limits, Londres. The MIT Press, 2014.

Aransay Alejandre, Ana María, “Antecedentes y propuestas para la regulación jurídica de los robots”, en Barrio Andrés, Moisés, Derecho de los Robots, Madrid, Wolters Kluwer, 2a Edición, 2019.

Baggini, Julian, El cerdo que quería ser jamón: y otros noventa y nueve experimentos para filósofos de salón, Paidós, 2007.

Ballesteros, Jesús, "Sergio Cotta y los retos del Siglo XXI." Persona y Derecho, no. 57, Diciembre 2007.

Barak, Aharon, Human Dignity: The Constitutional Value and the Constitutional Right, Cambridge University Press, 2015.

Baricco, Alessando, The Game, Anagrama, 2019.

Barrio Andrés, Moisés, "Hacia una person alidad electrónica para los robots", en Revista de Derecho Privado, no. 2, marzo 2018.

Barrio Andrés, Moisés, "Hacia una personalidad electrónica para los robots." Revista de Derecho Privado, no. 2, Marzo 2018.

Barrio Andrés, Moisés, “Robótica, inteligencia artificial y Derecho”, en ARI 103/2018 $-7 / 9 / 2018$.

Bartra, Roger, Cerebro y Libertad. Ensayo sobre la moral, el juego y el determinismo. México, Fondo de Cultura Económica, 2017.

Bostrom, Nick, Superinteligencia: caminos, peligros, estrategias, Teell Editorial, 2016.

Campione, Roger, “A vueltas con el Transhumanismo: cuestiones de futuro imperfecto", Cuadernos Electrónicos de Filosofía del Derecho, Número 40, 2019.

Campuzano Gallegos, Adriana, Inteligencia Artificial para abogados. Ya es tiempo..., México, Thomson Reuters, 2019.

Carnelutti, Francesco. Cómo nace el derecho. Bogotá, Editorial Temis, 2010.

Cotta, Sergio. Il diritto nell' esistenza; Linee di ontofenomenologia giuridica. Milano, Giuffré Editore, Seconda edizione, 1991.

Cotta, Sergio. La sfida tecnologica, Bologna, Il Mulino, 1968.

Damasio, Antonio, La sensación de lo que ocurre; cuerpo y emoción en la construcción de la conciencia, México, PAIDOS, 2019. 
Dawes, James, "Speculative Human Rights”, en Human Rights Quarterly, Volume 42, Number 3, August 2020, Disponible en: DOI: 10.1353/hrq.2020.0033.

De Lucas, Javier, Blade Runner; El Derecho, guardián de la diferencia, México, Tirant lo Blanch, 2012.

Dodig Crnkovic, Gordana, "Floridi’s Information Ethics as Macro-Ethics and Info-Computational", Research Gate, 6 junio 2016, Disponible en: DOI: 10.1007/978-94-007-4292-5_1

Etinson, Adam, "What's so special about human dignity?", en Philosophy \&t Public Affairs 48, no. 4, 2020.

Fagan, Andrew, Human Rights; Confronting Myths and Misunderstandings, Camberley, Edward Elgar, 2009.

Freeman, Michael, Human Rights, Cambridge, Polity, Third Edition, 2017.

Froomkin, A. Michel, "Prólogo” en Barrio Andrés, Moisés, Derecho de los Robots, Madrid, Wolters Kluwer, 2a Edición, 2019.

García Huidobro, Joaquín, El anillo de Giges; Una introducción a la tradición central de la ética, México, Notas Universitarias, 2020.

García-Prieto Cuesta, Juan “¿Qué es un robot?” en Barrio Andrés, Moisés, Derecho de los Robots, Madrid, Wolters Kluwer, 2a Edición, 2019.

Gewirth, Alan, The Community of Rights, Chicago, The University of Chicago Press, 1996.

Gunkel, David J., "The other question: can and should robots have rights?", en Ethics Inf Technol, 20, 2018.

Hakli, Raul, "Social robots and social interaction”, en J. Seibt et al. (Eds.), Sociable Robots and the Future of Social Relations, IOS Press, 2014.

Harari, Yuval Noah, 21 lecciones para el siglo XXI, México, Debate, 2020.

Hopkins, Patrick, "Is Enhancement worthy of being a right?”, en More, Max y Vita-More, Natasha, The transhumanist reader, Oxford, Wiley-Blackwell, 2013.

Koops, Hildebrandt and Jaquet-Chiffell, "Bridging the Accountability Gap: Rights for New Entities in the Information Society?” Minnesota Journal of Law, Science \& Technology, Vol. 11, No. 2, 2020.

Lariguet, Guillermo. “Humano, Demasiado Humano: ¿Podrían Tener Derechos Morales (Algunos) Robots? Un Análisis Filosófico a Partir De Dos Cuentos De Isaac Asimov." Principia Iuris 15, no. 28 (Julio 2017).

Lexcellent, Christian, Artificial Intelligence versus Human Intelligence; Are Humans Going to Be Hacked? Cham, Springer, 2019.

Llano Alonso, Fernando, Homo Excelsior. Los límites ético-jurídicos del transhumanismo, Tirant lo Blanch, 2018.

Mancosu, Paola, "Repensar lo humano. Aproximaciones post-dualistas a la obra de Gamaliel Churata”, en Bulletin of Hispanic Studies, 97, no. 8, septiembre 2020, doi:10.3828/bhs.2020.49.

Martínez García, Jesús Ignacio, "Inteligencia y derechos humanos en la sociedad digital”, en Cuadernos Electrónicos de Filosofía del Derecho, Número 40, 2019. 
MCmillan, Marianna., “Una mirada a la robótica desde los derechos humanos”, Persona y Derecho, no. 79, Julio 2018, p. 264. Ver también de Asís, Rafael., Una mirada a la robótica desde los derechos humanos, Madrid, Dykinson, 2015.

Medina Parra, Rosa Isabel, "Derechos humanos en México: entre la modernidad, posmodernidad y ultramodernidad", en Revista de Ciencias Sociales y Humanidades, Volumen 29, Número 57, Enero-Junio 2020, Disponible en: DOI: http:// dx.doi.org/10.20983/noesis.2020.1.7.

Meneke, Christoph y Pollmann, Arnd, Filosofía de los Derechos Humanos, Barcelona, Herder, 2010.

Monin, Maxim Aleksandrovich, Terekhova, Vera Albertovna y Ledeneva, Elena Vladimirovna, "The Chinese Room Argument in the Context of the Rational Action Theory." Utopía y Praxis Latinoamericana 25, Octubre 2020, pp.179-86. doi:10.5281/zenodo.3984228.

Palacios, Leopoldo-Eulogio, “La persona humana”, Verbo, núm. 495-496 2011.

Pichardo, Luz María, "Reinventing Bioethics in a Post-humanist and Post-truth Society. The Present and Future of Bioethics", en Pers. Bioét. 22(2), 2018.

Prieto Sanchís, Luis. El constitucionalismo de los derechos; Ensayos de filosofía jurídica. Madrid, Editorial Trotta, 2013.

Ramírez García, Hugo Saúl y Pallares Yabur, Pedro de Jesús, Derechos Humanos, México, Oxford University Press, 2011.

Ramírez-García, Hugo Saúl y Díez Spelz, Juan Francisco, La autenticidad y el fundamento de los derechos humanos. Una aproximación desde la filosofía jurídica de Sergio Cotta. Madrid, Universidad Complutense de Madrid, 2016.

Rodríguez Palop, María Eugenia, Claves para entender los nuevos derechos humanos, Madrid, Catarata, 2011.

Rodríguez Puerto, M. J. y Robles, G., “Algunas precisiones en torno a los derechos humanos”, en Megías Quirós, José Justo, Manual de Derechos Humanos: los derechos humanos en el siglo XXI, Thomson Aranzdi, 2006.

Salardi, Silvia, "Robótica e Inteligencia artificial: retos para el derecho", en Revista Derechos y Libertades, no. 42, enero 2020, Disponible en: doi: 10.14679/1158.

Solaiman, S M. "Legal personality of robots, corporations, idols and chimpanzees: a quest for legitimacy", Artificial Intelligence and Law, University of Wollongong, 25 (2), 2017.

Sparrow, Rob, “Can machines be people? Reflections on the Turing Triage Test”, en Lin, Patrick, Abney, Keith y Bekey, George A., Robot Ethics: The ethical and social implications of robotics, Massachusetts Institute of Technology, 2012.

Tasioulas, John, “The Rule of Law”, en Tasioulas, J. (Ed)., The Cambridge Companion to The Philosophy of Law, Cambridge, 2020.

Travieso, Juan Antonio, "Las personas jurídicas en el nuevo derecho y tecnología. Bienvenidos los robots", en Bielli, Gaston E., Mora, Santiago J. y Fernández, Diego (Dirs.), \#LegalTech II. El Derecho ante la tecnología, Thomson Reuters, 2019. 
Urueña, René, “Autoridad Algorítmica: ¿cómo empezar a pensar la protección de los derechos humanos en la era del 'Big Data'?” en Latin American Law Review, no. 2, enero 2019.

Valentini, Laura, Dignity an, d Human Rights: A Reconceptualisation, Oxford Journal of Legal Studies, Vol. 37, No. 4, 2017, doi:10.1093/ojls/gqx011.

Veatch, William S., The New Logic of the Law; Building a Foundation for Artificial Intelligence in the Law, Kindle Edition, 2018.

Vinge, Vernor, “Technological singularity”, en More, Max y Vita-More, Natasha, The transhumanist reader, Oxford, Wiley-Blackwell, 2013. Véase también Agar, Nicholas, Truly human enhancement; A philosophical defense of Limits, Londres. The MIT Press, 2014.

Viola, Francesco, “La ética de los derechos”, en Doxa, núm. 22, 1999.

Waldron, Jeremy, "Rights and Human Rights", en Tasioulas, J. (Ed)., The Cambridge

Companion to The Philosophy of Law, Cambridge, 2020.

Waldron, Jeremy, Law and Disagreement, Oxford University Press, 1999.

Wallach, Wendell Arnhold, "Moral Machines and Human Ethics “, en J. Seibt et al. (Eds.), Sociable Robots and the Future of Social Relations, IOS Press, 2014.

Weston, Burns H, "Human Rights: Concept and Content", in Weston, Burns H., and Grear, Anna, Human Rights in the World Community; Issues and Action, University of Pennsylvania Press 2016.

Otras fuentes

Comité Económico y Social Europeo, “Dictamen del Comité Económico y Social Europeo sobre la «Inteligencia artificial: las consecuencias de la inteligencia artificial para el mercado único (digital), la producción, el consumo, el empleo y la sociedad", Pleno No. 526, 2917/C 288/01 31 mayo 2017.

“Carta abierta” a la Comisión Europea sobre Inteligencia Artificial y Robótica. Disponible en: http://www.robotics-openletter.eu/

Delcker, Janosch, "Europe divided over robot "Personhood", Politico, 11 abril 2018. Consultado en la dirección URL:

$<$ https://www.politico.eu/article/europe-divided-over-robot-ai-artificial-intelligence-personhood/ $>$.

Diccionario de la Real Academia Española, voz "Robot”, [Consultada el 7 de septiembre de 2020] Disponible en: https://dle.rae.es/robot

“Etimología de inteligencia”, en Diccionario Etimológico Español en Línea, Disponible en: http://etimologias.dechile.net/?inteligencia

García, José, “¿Tienen que tener los robots los mismos derechos y obligaciones que nosotros?”, en La Información, 28 de enero 2018, Disponible en:

https://www.lainformacion.com/economia-negocios-y-finanzas/tienen-que-tener-los-robots-los-mismos-derechos-y-obligaciones-que-nosotros/6340964/ 
Grupo Europeo sobre Ética de la Ciencia y las Nuevas Tecnologías. Declaración sobre Inteligencia artificial, robótica y sistemas “autónomos”, Bruselas, 9 marzo 2018, Disponible en:

http://www.bioeticayderecho.ub.edu/archivos/pdf/EGE_inteligencia-artificial.pdf

Resolución del Parlamento Europeo, de 16 de febrero de 2017, con recomendaciones destinadas a la Comisión sobre normas de Derecho civil sobre robótica (2015/2103(INL). Disponible en: europarl.europa.eu/doceo/document/ TA-8-2017-0051_ES.html

The Toronto Declaration: Protecting the right to equality and non-discrimination in machine learning systems, Disponible en:

https://www.accessnow.org/cms/assets/uploads/2018/08/The-Toronto Declaration ENG_08-2018.pdf

Zamarriego, Laura, "El hombre y la máquina”, en ethic, Disponible en: https://ethic. es/2019/01/tecnologia-y-etica-era-maquinas/ 